\title{
Hypothalamic, pituitary and gonadal hormone production in relation to nutrition in the male hyrax (Procavia capensis)
}

\author{
R. Millar* and N. Fairall $\dagger$ \\ * M.R.C. Protein Research Unit, Department of Chemical Pathology, Medical School, Observatory, \\ Cape Town and $\dagger$ Department of Nature Conservation, Cape Town, South Africa
}

The influence of under-nutrition on reproduction in laboratory and domestic animals, as well as in man, is well recognized, and has been the subject of considerable investigation (see Sadleir, 1969; Howland, 1975). In wild animals, studies on the effects of nutrition on the onset and duration of the mating season and the degree of sexual activity have been mainly restricted to field observations (Verme, 1965; Stodart \& Meyers, 1966) rather than experimental investigation.

The seasonally breeding rock hyrax (Procavia capensis) inhabits a wide range of habitats in South Africa and is subject to considerable variation in the availability of food in different localities, and within the same locality in different years. Nutrition appears to affect the onset of puberty, since a greater percentage of males achieve puberty in their 1st year of life when nutritional conditions are improved by increased rainfall (Millar, 1971). It is not known if reproduction in adult males is affected by nutrition, but litter size is generally lower in more desert-like regions and a reduction in litter size occurs in years of diminished rainfall (Millar, 1971).

The present investigation was therefore undertaken to determine the effects of different planes of nutrition on spermatogenesis and androgenesis in males during the mating season, and to establish whether there were associated changes in anterior pituitary and hypothalamic hormone secretion.

Six adult male hyrax were individually caged in an animal house which was exposed to natural annual changes in photoperiod. In a preliminary study the daily intake of food necessary for maintenance of body weight was determined. Three hyrax with a mean body weight of $2799 \mathrm{~g}$ were then given a high-plane daily diet of $348 \mathrm{kcal}$ ( $200 \mathrm{~g}$ fresh lucerne and $50 \mathrm{~g}$ commercial rabbit pellets). The other 3 hyrax, mean body weight of $2712 \mathrm{~g}$, received a low-plane daily diet of $160 \mathrm{kcal}$ which consisted of $200 \mathrm{~g}$ fresh lucerne and $5 \mathrm{~g}$ pellets. Feeding regimens commenced in December and continued until the height of the mating season in mid-February, when the animals were anaesthetized by an i.p. injection of $480 \mathrm{mg}$ Nembutal (Abbott Laboratories) and exsanguinated by cardiac puncture. For comparative purposes 5 wild males which were sexually quiescent were shot at the end of the mating season in May.

The blood was collected in heparinized tubes, centrifuged and the plasma stored at $-20^{\circ} \mathrm{C}$ until assay. The brain was removed immediately after death and a discrete hypothalamic area between the optic chiasma and mamillary bodies was dissected out to a depth of $4 \mathrm{~mm}$. The entire pituitary was removed and both organs stored over solid $\mathrm{CO}_{2}$. The testes were removed and weighed and a slice of each testis was fixed in $10 \%$ formol saline and routinely processed for histological examination. The mean seminiferous tubule diameter was estimated by measurement of 10 randomly chosen circular sections in each testis.

Testosterone was measured in the plasma samples by a radioimmunoassay employing an antiserum highly specific for testosterone and exhibiting only 5-6\% cross-reaction with dihydrotestosterone (Millar \& Kewley, 1975). Plasma cortisol was estimated by the fluorimetric method (Mattingly, 1962). Concentrations of LH in plasma and homogenates of pituitaries in phosphate-buffered saline were measured by a modification of the radioimmunoassay for rat LH (Niswender, Midgely, Monroe \& Reichert, 1968) and using the antiserum of Niswender et al. to ovine LH (GDN 15), iodinated rat LH (NIAMDD) and ovine standards (NIAMDD ovine-LH-S18). Validation of this assay for quantitating hyrax $\mathrm{LH}$ has been demonstrated by various criteria, including a comparison 
of hyrax pituitary LH concentration by the ovarian ascorbic acid depletion biological assay (R. P. Millar \& C. Aehnelt, unpublished).

Individual hypothalami were homogenized in $2 \mathrm{ml}$ phosphate-buffered saline and then heated for $5 \mathrm{~min}$ in a boiling water bath to inactivate endogenous peptidases known to degrade $\mathrm{LH}-\mathrm{RH}$ (Griffiths, Hooper \& Hopkinson, 1973; Kuhl \& Taubert, 1975; Gradwell, Millar \& Symington, 1976). After centrifugation and appropriate dilution of the supernatant, LH-RH content was determined by radioimmunoassay with a specific antiserum raised to LH-RH conjugated to keyholelimpet haemocyanin and ${ }^{125}$ I-labelled LH-RH (Hendricks, Millar \& Pimstone, 1975).

At the end of the experiment, the mean bodyweight of the animals on a high plane of nutrition had increased by $268 \mathrm{~g}$ whilst that of hyrax on the low-plane diet had decreased by $224 \mathrm{~g}$.

The effect of the two planes of nutrition on various parameters of reproduction is shown in Table 1. Testicular weight, seminiferous tubule diameter and plasma testosterone concentration were all significantly lower in hyrax fed a low-plane diet than in hyrax on a high plane of nutrition. Plasma and pituitary LH were also lower in the former group but this difference was not statistically significant. Hypothalamic LH-RH and plasma cortisol levels did not differ in the two groups. In general, the results of the parameters studied (Table 1) were intermediate for the animals on a low plane of nutrition between those for hyrax fed a high-plane diet and sexually quiescent animals.

Table 1. Comparison of testicular activity and hormone concentrations in sexually active hyrax on a high or low plane of nutrition and wild sexually quiescent hyrax (no. in parentheses)

\begin{tabular}{|c|c|c|c|}
\hline & \multicolumn{2}{|c|}{ Sexually active hyrax } & \multirow{2}{*}{$\begin{array}{c}\text { Sexually quiescent } \\
\text { hyrax (5) }\end{array}$} \\
\hline & High plane diet (3) & Low plane diet (3) & \\
\hline Wt of testes (g) & $86 \cdot 2 \pm 8 \cdot 2^{\mathrm{ab}}$ & $48 \cdot 2 \pm 5 \cdot 2^{\mathrm{ac}}$ & $5 \cdot 6 \pm 1 \cdot 8^{b c}$ \\
\hline Seminiferous tubule diameter $(\mu \mathrm{m})$ & $192 \cdot 3 \pm 0 \cdot 3^{\mathrm{ab}}$ & $143 \cdot 2 \pm 7 \cdot 6^{\mathrm{ac}}$ & $67 \cdot 0 \pm 3 \cdot 9^{b c}$ \\
\hline Plasma testosterone $(\mathrm{ng} / \mathrm{ml})$ & $13 \cdot 6 \pm 3 \cdot 2^{\mathrm{ab}}$ & $2.5 \pm 0.6^{a}$ & $1 \cdot 18 \pm 0.06^{b}$ \\
\hline Plasma LH* (ng/ml) & $5 \cdot 5 \pm 2 \cdot 8$ & $1.0 \pm 0.3$ & $2 \cdot 9 \pm 2 \cdot 0$ \\
\hline Pituitary $\mathrm{LH}^{*}(\mu \mathrm{g} /$ gland $)$ & $210 \cdot 7 \pm 40 \cdot 5^{b}$ & $147 \cdot 3 \pm 11 \cdot 7^{c}$ & $63 \cdot 5 \pm 21 \cdot 9^{b c}$ \\
\hline Hypothalamic LH-RH (ng/gland) & $16 \cdot 5 \pm 4 \cdot 3^{b}$ & $21 \cdot 5 \pm 7 \cdot 3^{\mathrm{c}}$ & $101 \cdot 6 \pm 13 \cdot 9^{b c}$ \\
\hline Plasma cortisol $(\mu \mathrm{g} / 100 \mathrm{ml})$ & $6.6 \pm 0.7$ & $5 \cdot 6 \pm 1 \cdot 2$ & $3 \cdot 4 \pm 1 \cdot 1$ \\
\hline
\end{tabular}
$t$ test.

Values are means \pm S.E.M.; means bearing identical superscripts differ significantly $(\mathrm{p}<0.05)$ by Students

* Expressed in terms of NIAMDD-ovine-LH-S18.

Although several field studies have shown a relationship between male fertility and rainfall or nutrition (see review by Sadleir, 1969), it is uncertain whether improved nutrition per se stimulates the reproductive organs, or whether a predictive environmental cue such as photoperiod triggers reproduction to make use of seasonal improvements in vegetation. Photoperiod is the major environmental cue for the mating season in hyrax (Millar \& Glover, 1973), but it is clear from the present results that nutrition has a modifying influence. Spermatogenesis, as indicated by increased seminiferous tubule diameter (Millar \& Glover, 1970, 1973), and testosterone production were decreased in hyrax on the lower plane of nutrition. Studies on animals of other species have suggested that reduced reproduction is not due to failure of the gonads but is a result of diminished gonadotrophic hormone production (Allen \& Lamming, 1961; Mann, Rowson, Short \& Skinner, 1967; Gombe, Apgar \& Hansel, 1973; Howland, 1975). Although circulating levels of $\mathrm{LH}$ were reduced in the hyrax on a low-plane diet, the difference was not significant, perhaps because of the episodic nature of LH secretion. Howland (1975) has also found that when male rats were underfed for 15 or 20 days, plasma testosterone was significantly decreased but the reduction in plasma LH was not statistically significant.

The present results also suggest that the nutritional effects on reproduction were primarily due to alterations in the secretion of LH-RH. Although LH-RH is undetectable in the circulation, we have previously observed an inverse relation between hypothalamic LH-RH content and plasma LH concentration, and such a correlation appears true for the present results. Sexually quiescent 
hyrax had high hypothalamic LH-RH levels and low plasma LH. The higher mean hypothalamic LH-RH in low-plane hyrax compared with high-plane animals therefore implies a decrease in release of the hormone. However, as with $\mathrm{LH}$, the difference was not statistically significant and further studies using larger numbers of animals are indicated.

Since reproductive processes increase the energy requirements of animals, the selective advantage of reducing or halting reproduction in response to poor nutrition may be appreciated. Whether it is a general calorie restriction, a deficiency in a specific dietary component, or a consequent change in circulating plasma nutrients which influences the secretion of gonadotrophic hormone-releasing hormones, remains to be elucidated. However, the recent report of an increase in LH, FSH and testosterone secretion within 1 day of re-feeding starved male rats (Howland, 1975) points to a direct dietary effect as opposed to an indirect one mediated via a general gain in body weight.

We thank Professor J. E. Kench and Dr D. Hey for their support and Miss C. Aehnelt for invaluable technical assistance. Dr E. Polakow (Ayerst Laboratories) kindly supplied LH-RH. We are grateful to Dr G. D. Niswender, Dr L. E. Reichert and the NIAMDD for LH radioimmunoassay materials. The work was supported by grants from the Medical Research Council and University of Cape Town.

\section{References}

Allen, D.M. \& Lamming, G.E. (1961) Nutrition and reproduction in the ewe. J. agric. Sci., Camb. 56, 69-79.

Gombe, S., Apgar, I. \& Hansel, W. (1973) Effect of zinc deficiency and restricted food intake on plasma and pituitary LH and hypothalamic LRF in female rats. Biol. Reprod. 9, 415-419.

Gradwell, P.B., Millar, R.P. \& Symington, R.B. (1976) Failure to demonstrate high concentrations of luteinizing hormone-releasing hormone in the bovine pineal body. S. Afr. Med.J. 50, 217-219.

Griffiths, E.C., Hooper, K.C. \& Hopkinson, C.R.N. (1973) Evidence for an enzymic component in the rat hypothalamus capable of inactivating luteinizing hormone releasing factor (LRF). Acta endocr., Copenh. 74, 49-55.

Hendricks, S., Millar, R. \& Pimstone, B. (1975) A specific radioimmunoassay for gonadotrophinreleasing hormone. S. Afr. Med. J. 49, 15591562.

Howland, B.E. (1975) The influence of food restriction and subsequent refeeding on gonadotrophin secretion and serum testosterone levels in male rats. J. Reprod. Fert. 44, 429-436.

KUHL, H. \& TAUBERT, H.-D. (1975) Inactivation of luteinizing hormone releasing hormone by rat hypothalamic L-cystine arylamidase. Acta endocr., Copenh. 78, 634-648.

Mann, T., Rowson, L.E.A., Short, R.V. \& Skinner, J.D. (1967) The relationship between nutrition and androgenic activity in pubescent twin calves, and the effect of orchitis. $J$. Endocr. 38, 455-468.

Mattingly, D. (1962) A simple fiuorimetric method for the estimation of free 11-hydroxycorticoids in human plasma. J. clin. Path. 15, 374-379.

MillaR, R.P. (1971) Reproduction in the rock hyrax (Procavia capensis). Zool. Afr. 6, 243-261.

Millar, R.P. \& Glover, T.D. (1970) Seasonal changes in the reproductive tract of the male rock hyrax, Procavia capensis. J. Reprod. Fert. 23, 497-499.

Millar, R.P. \& Glover, T.D. (1973) Regulation of seasonal sexual activity in an ascrotal mammal, the rock hyrax, Procavia capensis. J. Reprod. Fert., Suppl. 19, 203-220.

Millar, R.P. \& Kewley, C. (1975) Production of a specific antiserum for testosterone. Proc. S. Afr. Assn. clin. Biochem. p. 77.

Niswender, G.D., Midgely, A.R., Monroe, S.E. \& REICHERT, L.E. (1968) Radioimmunoassay for rat luteinizing hormone with antiovine LH serum and ovine LH- ${ }^{131}$ I. Proc. Soc. exp. Biol. Med. 128, 807-811.

SADLEIR, R.M.F.S. (1969) The Ecology of Reproduction in Wild and Domestic Mammals. Methuen, London.

STODART, E. \& MEYERS, K. (1966) The effects of different foods on confined populations of wild rabbits, Oryctolagus cuniculus (L). C.S.I.R.O. Wildl. Res. 11, $111-124$.

VERME, L.J. (1965) Reproduction studies on penned white-tailed deer J. Wildl. Mgmt 29, 74-79.

Received 10 November 1975 